\title{
Ärzten steht neue Konkurrenz ins Haus
}

\begin{abstract}
Eine engere Verzahnung der Arbeit von Ärzten und Angehörigen der medizinischen Fachberufe wünschen sich beide Seiten. Der Gemeinsame Bundesausschuss hat jetzt in der Frage der Delegation und Substitution ärztlicher Leistungen Fakten geschaffen.
\end{abstract}

- Seit drei Jahren verhandelt der Gemeinsame Bundesausschuss (GBA) über die Heilkundeübertragungs-Richtlinie. Dabei geht es um die Delegation, inzwischen aber auch um die Substitution ärztlicher Leistungen durch Angehörige der Pflegeberufe. Diese werden aller Voraussicht nach demnächst in Modellversuchen wie eine neue Art von Leistungserbringern agieren.

Die Richtlinie wird Fakten schaffen. „De facto handelt es sich um die Substitution ärztlicher Tätigkeiten“, heißt es in Ärztekreisen. Aus den Pflegekräften werden Leistungserbringer. An dieser Stelle entsteht Konkurrenz. An den Modellverträgen zwischen Kassen und Pflegekräften, die nach Inkrafttreten der Richtlinie zu erwarten sind, seien Ärzte nicht beteiligt, so der Hauptgeschäftsführer der Deutschen Krankenhausgesellschaft (DKG), Georg Baum. Die Kassen kämen dem Ziel näher, „einen eigenstän-

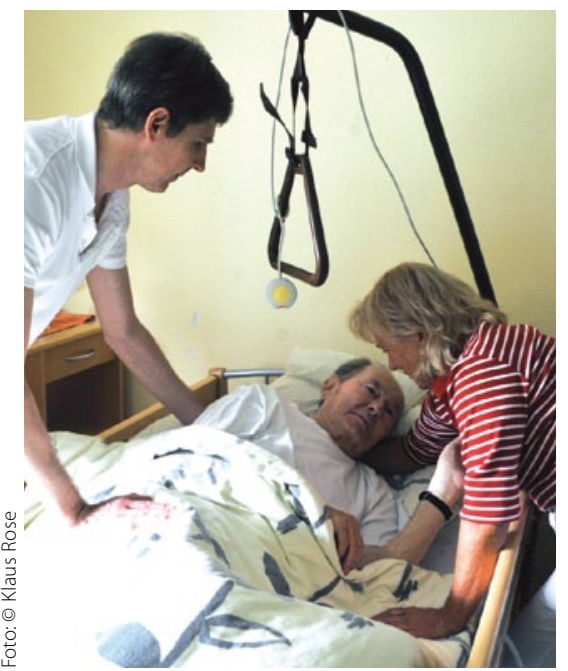

Bisher ärztliche Leistungen sollen von Pflegekräften erbracht werden.

digen neuen Sektor in der ambulanten Behandlung zu schaffen in der Hoffnung, teure ärztliche Leistung durch billigere pflegerische Leistungen zu ersetzen“.
Bei der DKG sieht man die Substitution ärztlicher Leistungen allerdings gelassener. Im Krankenhaus blieben ja alle Beteiligten als Angestellte weisungsgebunden.

Die Medizinischen Fachangestellten wie auch die Angehörigen anderer medizinischer Fachberufe tauchen in der Richtlinie nicht auf. Gut finden deren Vertreter das nicht. „Wir hätten uns von den Ärzten mehr Mut gewünscht. In der Delegation wurden ja durchaus Zugeständnisse gemacht. Beim Thema Substitution wird hingegen sofort jede Diskussion beendet", sagte Arndt Longrée, Vorsitzender des Deutschen Verbands der Ergotherapeuten. Zugeständnisse seien aber mit Blick auf den drohenden Ärztemangel sinnvoll. Die Fachberufe könnten ihren jeweiligen Anteil an der Behandlung leisten und sollten dafür auch mehr Spielraum bekommen.

Dass darunter die Qualität leiden könnte, sieht Longrée nicht. „Die Modellprojekte müssen eine sehr hohe Hürde nehmen, alleine was die Wirtschaftlichkeit, Wirksamkeit und Patientensicherheit angeht", so Longrée. AF/SUN -

\section{Wichtig für Hartz-IV-Bezieher und kinderreiche Familien}

\section{Das grüne Rezept kann den Patienten helfen}

- Rezeptfreie Arzneimittel müssen von Patienten zwar in der Regel selbst bezahlt werden - für Empfänger von Hartz-IV-Leistungen können sie jedoch einen besonderen Hilfebedarf auslösen, der unter Umständen erstattet werden kann.

Für rezeptfreie Arzneimittel belegt das Grüne Rezept, dass der Arzt eine
Verordnung für notwendig und zweckmäßig gehalten hat; es kann daher, zusammen mit einer vom Apotheker ausgestellten Quittung bei der Arbeitsagentur vorgelegt werden, um Hilfebedarf geltend zu machen.

Ferner können Grüne Rezepte zusammen mit Belegen über Zuzahlungen (Praxisgebühr, Rezeptgebühr oder Auf- zahlungen bei Leistungen, für die ein Festbetrag oder Festzuschuss gilt) bei der Einkommensteuer als außergewöhnliche Belastung geltend gemacht werden. Besonders relevant ist das für Familien mit drei und mehr Kindern, für die eine Zumutbarkeitsgrenze von nur einem Prozent des Jahreseinkommens (bis 51000 Euro) gilt. 